Citation: Roy S et al. (2019) "Successful extracorporeal membrane oxygenation in the management of acute respiratory distress syndrome and cardiopulmonary collapse secondary to amniotic fluid embolism"

The VAD Journal, 5. doi: https://doi.org/10.13023/VAD.2019. 04

Editor-in-Chief: Maya Guglin, University of Kentucky

Received: February 4, 2019

Accepted: February 22, 2019

Published: March 11, 2019

(C) 2019 The Author(s). This is an open access article published under the terms of the Creative Commons Attribution-

NonCommercial 4.0 International License

(https://creativecommons.org/licens es/by-nc/4.0/), which permits unrestricted non-commercial use, distribution, and reproduction in any medium, provided that the original author(s) and the publication source are credited. Funding: This case report is supported by the Rochester General Hospital Internal Medicine Residency Program, Rochester Regional Health, Rochester, NY Competing interests: none

\section{Successful Extracorporeal Membrane Oxygenation in the Management of Acute Respiratory Distress Syndrome and Cardiopulmonary Collapse Secondary to Amniotic Fluid Embolism}

\author{
Sumon Roy ${ }^{1}$, Nishit Biniwale', Venkata Pendela ${ }^{1}$, Patricia Oates ${ }^{2}$,
}

\author{
Katrina Wojciechowski ${ }^{2}$, and Scott Feitell ${ }^{*}$ \\ 'Department of Medicine, Rochester General Hospital, Rochester Regional Health \\ System \\ ${ }^{2}$ Sands-Constellation Heart Institute, Rochester Regional Health System
}

Corresponding author: scott.feitell@rochesterregional.org

\begin{abstract}
Amniotic fluid embolism (AFE) is one of the most devastating complications of pregnancy that typically manifests as acute cardiopulmonary collapse during delivery or in the postpartum period. The potential role of extracorporeal membrane oxygenation (ECMO) as a management technique in severe cases of AFE remains largely unknown. In this report, we present the first case, to our knowledge, of successful implementation of ECMO as a life-saving measure in a case of hemorrhagic shock due to postpartum bleeding complicated by severe AFE leading to acute respiratory distress syndrome (ARDS) ultimately requiring tracheostomy. Hemodynamic decompensation is often rapid but transient in cases of severe AFE, and we recommend early consideration of ECMO implementation given its vital utility in these critical moments.
\end{abstract}

Keywords: heart failure, extracorporeal membrane oxygenation, amniotic fluid embolism 


\section{Introduction}

Extracorporeal membrane oxygenation (ECMO) was initially used as long-term support for severe respiratory failure in the 1970s. Widespread ECMO use had not been considered until the relatively recent CESAR trial described significant improvement in mortality and disability following ECMO intervention compared to conventional ventilatory support (1). Over the interval of four decades, limited randomized controlled trials have been completed investigating ECMO applicability (1-4). Therefore, much remains unknown about the potential utility of ECMO in various clinical settings.

Amniotic fluid embolism (AFE), reported as early as 1926, has an incidence of 1 in 40,000 deliveries with a mortality that can approach $60 \%(5,6)$. AFE heralds from a breach in the maternal-fetal barrier during parturition leading to fetal tissue exposure to the mother resulting in a complex clinical presentation (Figure 1).

\section{Figure 1}

Pathophysiology of amniotic fluid embolism

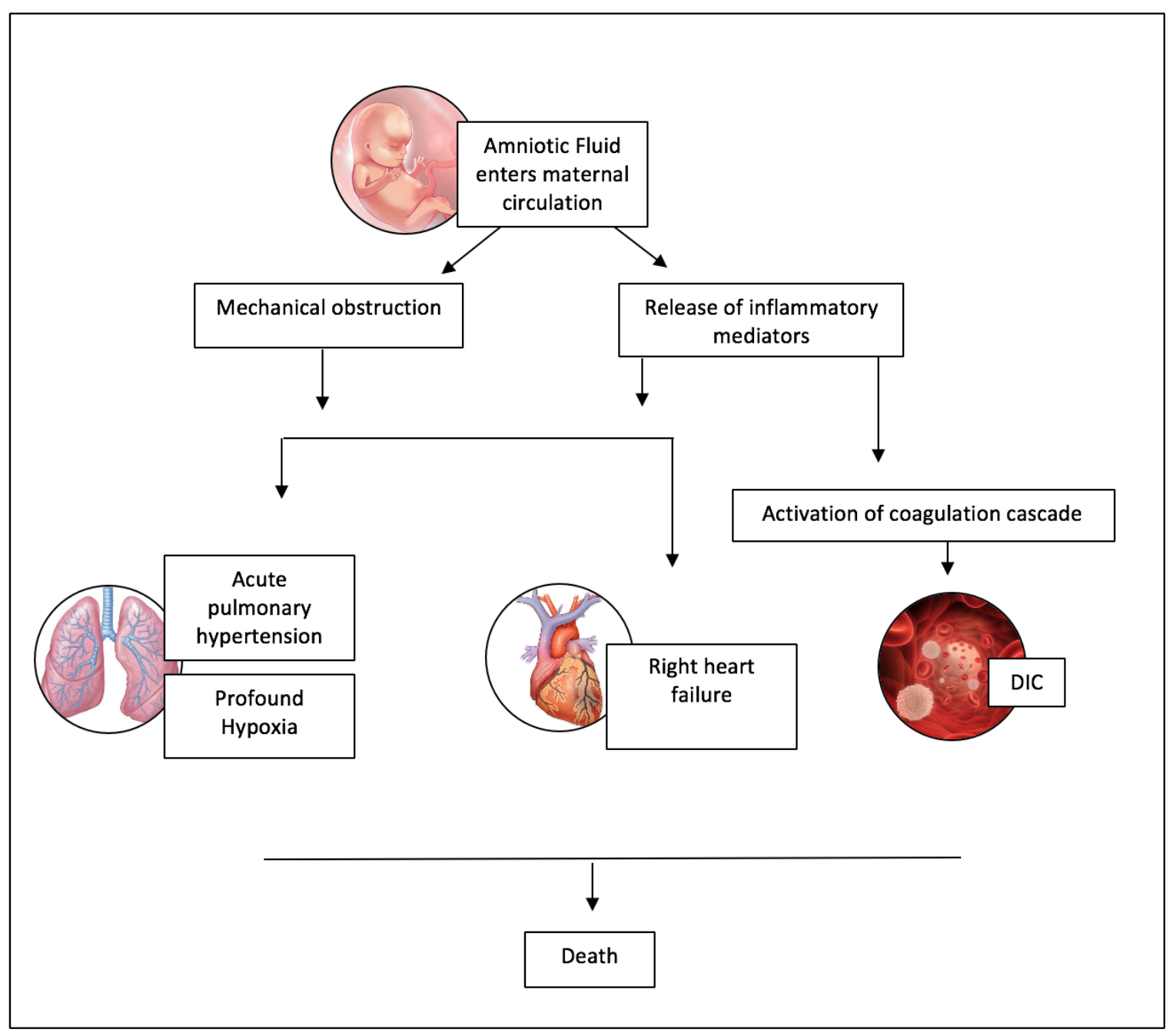


Clinical manifestations typically seen include hypoxia, hypotension and coagulopathy, which can rapidly progress resulting in cardiac arrest and death (7). AFE is often diagnosed on clinical suspicion, and proceeding with emergent management is necessary since hemodynamic decompensation may be transient and recoverable within hours (8).

The foundation of maintaining hemodynamic support is essential in AFE intervention, focusing on blood pressure augmentation and oxygenation support. There is a paucity of literature describing advanced hemodynamic support in cases of AFE, with isolated reports of survival associated with the use of ECMO, intra-aortic balloon counter pulsation, and continuous hemodiafiltration have been described but are still currently generally regarded as experimental approaches (811).

To our knowledge, the case we present here is the first report of AFE-induced hemorrhagic shock successfully managed with veno-venous (VV) ECMO in a patient with anti-cardiolipin antibody syndrome.

\section{Case}

A 37-year-old G3P0020 female with known anti-cardiolipin antibodies being managed with low molecular weight heparin and aspirin during pregnancy was admitted to the hospital for induction of labor in the 39th week of gestation. On hospital day two, a Caesarian section was performed, which was complicated by severe post-partum hemorrhage requiring massive transfusion, tranexamic acid and uterine tamponade.

Despite anticoagulation being held 24 hours prior to the procedure, within one hour of Caesarian section the patient developed post-partum hemorrhage requiring blood products. Hemodynamic instability persisted leading to hypoxic respiratory failure ultimately requiring intubation within six hours of the procedure. The patient remained hypoxic and cyanotic on maximal ventilator settings and profoundly hypotensive. In addition, she experienced recurrent bleeding that necessitated emergent bedside hysterectomy. AFE was suspected due to the sudden dire hypoxia and hypotension, and she was subsequently placed on VV ECMO within 12 hours of Caesarian section. The double cannulas were placed in the bilateral femoral veins, and anticoagulation with heparin was initiated to support ECMO.

On post-operative day one, she continued to require blood products while remaining ventilator-dependent, with chest X-ray findings suggestive of ARDS. Blood pressure was maintained in acceptable range with vasopressor support. She required multiple trips to the operating room for abdominal exploration and washout due to intra-abdominal bleeding requiring institution of massive transfusion protocol. Due to persistent post-partum hemorrhage, ECMO was continued without anticoagulation. Eventually, bleeding was controlled and vital signs began to show improvement. Electrolytes, renal function, and hepatic parameters remained preserved during the hospital course. After 10 days, the patient was decannulated and taken off ECMO support, and she was discharged home with minimal sequelae. 


\section{Discussion}

This report describes a unique presentation of AFE-induced hemorrhagic shock and profound bleeding that required advanced life support measures in the form of ECMO. This case complements an extremely limited literature base discussing the potential utility of ECMO in the management of AFE. Furthermore, to our knowledge, this is the first report of ECMO support in the management of AFEinduced hemorrhagic shock in a patient with a known hypercoagulable disorder.

AFE was suspected to be the etiology of hemodynamic compromise in this case because of the clinical presentation with marked rapid decline in the hours shortly following Caesarian section. During this interval and prior to transfusion of blood products, critical hypoxia and hypotension persisted despite maximal support. In addition, pathological analysis of uterus and placenta samples was suggestive of placenta accreta, which is an established risk factor for AFE (12-14).

The underlying diagnosis of anticardiolipin antibody syndrome likely significantly contributed to the patient's challenging hospital course. Her hematological disorder predisposed her to profound bleeding, leading to critical hemorrhage during and after Caesarian delivery. Recurrent bleeding required several emergent trips to the operating room leading to the decision to run the ECMO circuit without heparin. After stopping anticoagulation within hours of initiating ECMO, the relative frequency of bleeding episodes gradually declined. She was subsequently successfully maintained on the VV ECMO circuit without anticoagulation for approximately five days. Clotting within the ECMO circuit or the oxygenator was not observed during this time. On post-operative day six, post-partum bleeding had ceased with blood levels stable, and the surgical team closed the abdomen. Heparin was resumed for the remaining ECMO course without complication.

The timely incorporation of ECMO reversed an ill-fated hospital course of a patient with suspected AFE complicated by severe hemorrhagic shock and ARDS with persistent hypoxia despite maximal ventilator settings and paralysis. Risks associated with ECMO use in this setting include increased risk of bleeding in the setting of disseminated intravascular coagulation. However, hemodynamic decompensation is often rapid in cases of severe AFE, and we recommend early consideration of emergent ECMO implementation given its vital utility in these critical moments.

\section{Acknowledgments:}

This case report is supported by the Rochester General Hospital Internal Medicine Residency Program, Rochester Regional Health, Rochester, NY. 


\section{References}

1. Peek GJ, Mugford M, Tiruvoipati R, et al.: Efficacy and economic assessment of conventional ventilatory support versus extracorporeal membrane oxygenation for severe adult respiratory failure (CESAR): a multicentre randomised controlled trial. Lancet 2009;374:1351-63.

2. Bein T, Weber-Carstens S, Goldmann A, et al.: Lower tidal volume strategy ( approximately $3 \mathrm{ml} / \mathrm{kg}$ ) combined with extracorporeal CO2 removal versus 'conventional' protective ventilation $(6 \mathrm{ml} / \mathrm{kg}$ ) in severe ARDS: the prospective randomized Xtravent-study. Intensive Care Med 2013;39:847-56.

3. Morris $\mathrm{AH}$, Wallace $\mathrm{CJ}$, Menlove RL, et al.: Randomized clinical trial of pressure-controlled inverse ratio ventilation and extracorporeal $\mathrm{CO} 2$ removal for adult respiratory distress syndrome. Am J Respir Crit Care Med 1994;149:295305.

4. Zapol WM, Snider MT, Hill JD, et al.: Extracorporeal membrane oxygenation in severe acute respiratory failure. A randomized prospective study. JAMA 1979;242:2193-6.

5. Knight M, Tuffnell D, Brocklehurst P, Spark P, Kurinczuk JJ, System UKOS: Incidence and risk factors for amniotic-fluid embolism. Obstet Gynecol 2010;115:910-7.

6. Dildy GA, Belfort MA, Clark SL: Anaphylactoid syndrome of pregnancy (amniotic fluid embolism). In: Belfort M, Saade G, Foley M, Phelan J, Dildy GA, editors. Critical care obstetrics. Oxford (UK): Wiley-Blackwell; 2010. p. 466-74.

7. Gist RS, Stafford IP, Leibowitz AB, Beilin Y: Amniotic fluid embolism. Anesth Analg 2009;108:1599-602.

8. $\quad \mathrm{Ho} \mathrm{CH}$, Chen KB, Liu SK, Liu YF, Cheng HC, Wu RS: Early application of extracorporeal membrane oxygenation in a patient with amniotic fluid embolism. Acta Anaesthesiol Taiwan 2009;47:99-102.

9. Hsieh YY, Chang CC, Li PC, Tsai HD, Tsai CH: Successful application of extracorporeal membrane oxygenation and intra-aortic balloon counterpulsation as lifesaving therapy for a patient with amniotic fluid embolism. Am J Obstet Gynecol 2000;183:496-7.

10. Shen HP, Chang WC, Yeh LS, Ho M: Amniotic fluid embolism treated with emergency extracorporeal membrane oxygenation: a case report. J Reprod Med 2009;54:706-8.

11. Tincres F, Conil JM, Crognier L, Rouget A, Georges B, Ruiz S: Venoarterial extracorporeal membrane oxygenation in a case of amniotic fluid embolism with coexisting hemorrhagic shock: lessons learned. Int J Obstet Anesth 2018;33:99-100.

12. Price TM, Baker VV, Cefalo RC: Amniotic fluid embolism. Three case reports with a review of the literature. Obstet Gynecol Surv 1985;40:462-75. 
13. Conde-Agudelo A, Romero R: Amniotic fluid embolism: an evidence-based review. Am J Obstet Gynecol 2009;201:445 e1-13.

14. Society for Maternal-Fetal Medicine . Electronic address pso, Pacheco LD, Saade G, Hankins GD, Clark SL: Amniotic fluid embolism: diagnosis and management. Am J Obstet Gynecol 2016;215:B16-24. 